\title{
Research Output and Publications Impact of Postgraduate Institute of Medical Education and Research Chandigarh (1999-2008)
}

\author{
Raj Kumar, BM Gupta, JS Thakur, RK Sharma, Kiran Baidwan, Adrash Bala Goyal
}

\begin{abstract}
This paper attempts to analyze the research activities of the Postgraduate Institute of Medical Education and Research (PGIMER), Chandigarh as reflected in its 10 years cumulative (1999-2008) publications output covered in Scopus International multidisciplinary bibliographical database. The present study analyses the broad characteristics of 4,771 research papers published by the faculty members of PGIMER, Chandigarh by focusing on its publication growth characteristics, format and media of communication, research impact and quality, patterns of research collaboration, broad and narrow areas of research focus and characteristics of its high cited papers.
\end{abstract}

Keywords: PGIMER, Research output, Scientometrics.

How to cite this article: Kumar R, Gupta BM, Thakur JS, Sharma RK, Baidwan K, Goyal AB. Research Output and Publications Impact of Postgraduate Institute of Medical Education and Research Chandigarh (1999-2008). J Postgrad Med Edu Res 2012;46(3):129-137.

Source of support: Nil

Conflict of interest: None declared

\section{INTRODUCTION}

The Postgraduate Institute of Medical Education and Research (PGIMER), Chandigarh was conceived in 1960 as a center of excellence. The institute was started in 1962 and became an autonomous body under the Act of Parliament in 1967 functioning under the Ministry of Health and Family Welfare, Government of India. The main aim of PGIMER is to provide high quality patient care, attain self-sufficiency in postgraduate medical education and to meet the country's need for highly qualified medical professionals in all medical and surgical disciplines, provide educational facilities for the training of personnel in all important branches of health activity and undertake basic community-based research. The institute has 47 departments and 10 advanced care centers, like Advanced Pediatrics Center, Advanced Urology Centre, Bone Marrow Transplant Center, Advanced Eye Center, Advanced Cardiac Center, Oral Health Sciences Center, Renal Transplant Center, School of Public Health, Gastroenterology Center and Telemedicine Center. These 47 departments can further be classified as clinical, Paraclinical and nonclinical departments.

The PGIMER offers a variety of courses at undergraduate, graduate, postgraduate and doctoral levels.
The medical courses offered include MD/MS, in 20 disciplines Mch/DM, in 18 disciplines, MDS, Ph D and PostMD certificate. The paramedical undergraduate courses undertaken at the institute include BSc (Med. Tech. Laboratory, X-ray, Audiology and Speech therapy, Radiotherapy, Physical Therapy, Operation Theater, Per-fusionist) and Paramedical Postgraduate courses include MSc (Pathology, Microbiology, Radiology, Pharmacology and Physiology, Biochemistry, Speech and Hearing, Pharmacology, Biochemistry and Biotechnology). In the year 2006, National Institute of Paramedical Sciences (NIPS) was established for the paramedical undergraduate courses. Beside these courses, full-fledged institute of nursing also provides nursing courses, called National Institute of Nursing Education (NINE), which imparts quality-nursing education. This institute also imparts shortterm and elective training courses.

Research forms an integral part of the education program of the institute. Scientific inquiry includes basic research and clinic research. PGI has always made an endeavor to direct its various research activities to the relative needs of the society. The research work is carried out in accordance with nationally and internationally approved guidelines. All the departments undertake research in the area of national importance. A unique feature of research at this institute is the establishment of the Department of Experimental Medicine which helps various clinical departments to have an in-depth research at the level of molecular biology and basic sciences to correlate with the various clinical problems, e.g. hypertension, coronary artery disease, rheumatic heart diseases, malabsorption, etc. WHO and various national agencies have designated a number of departments of PGIMER as research/collaborative centers. The research output has been incredible and has found recognition at the various national and international forums. A number of scientific conferences/workshops/seminars are held in the institute throughout the year. The faculty members of the PGIMER had received several awards and recognitions for their scientific contribution to the profession and research.

A number of similar studies have already been undertaken by one of the authors for evaluation of various Indian institutions on the basis of their research output in India, like Indian Institute of Technology, Kharagpur, Indian Institute of Technology, Roorkee, University of 
Mysore, Government Medical College and Hospital, Chandigarh, etc. ${ }^{1-5}$

Dr Tulsi Das Library of PGIMER plays a very significant role in the patient care, research and academic activities of the institute. The main objectives of the present study are to analyze the broad characteristic features of the publications output of PGIMER, Chandigarh during 1999 to 2008. In particular, the study focuses on the growth, format and media of communication and impact of its research output; research output and impact under broad and narrow broad subject areas as well as by different subject departments; patterns of national and international collaboration and characteristics of highly cited papers and productive authors.

\section{METHODOLOGY AND DATABASE USED}

The present study uses 10 years publications output data from 1999 to 2008 for understanding the broad characteristics and impact of research of PGIMER, Chandigarh. For this purpose, the study derives publications output of PGIMER, Chandigarh from the publications covered in the Scopus International multidisciplinary bibliographical database. For analyzing the subject scope, we have divided the total research output under 47 already established subject departments. The research output is also considered under different subject areas as defined in Scopus database classification. In Scopus database classification, the entire science and technology literature has been classified under 20 broad subjects and four broad subject areas of physical, engineering, life and health sciences. In this paper, PGIMER contribution is considered for eight broad subjects, which are related to health sciences and life sciences. For assessing the impact and quality of publications output, the citations received during first 3 years (i.e. 3 years fixed citation window) were considered. It means for citations of papers for the year 2000 are counted from 2001 to 2003 (3 years window) and for the year 2001 counted from 2002 to 2004 and so on.

\section{RESULTS/ANALYSIS}

\section{Overall Research Profile}

As reflected in Scopus International bibliographical database, PGIMER has published 4,771 papers during 1999 to 2008, with an average of 477.1 papers per annum. The publications output of the institute has increased from 1,901 papers in 1999 to 2003 and 2870 papers in 2004 to 2008, showing growth rate of about $51 \%$. The institute achieved the average annual publication growth rate of $5.9 \%$ during 1999 to 2008 (Table 1).

Considering the quality and impact of papers published (1999-2008) in terms of average citation per paper, PGIMER has recorded an average impact of 1.98 citations per paper, which decreased from 2.35 citations per paper in 1999 to 2003 to 1.74 citations per paper during 2004 to 2008 (Table 2).

\section{Research Contribution of PGIMER in Broad Subject Areas}

The publication output of PGIMER under different subjects as defined by Scopus classification during 1999 to 2008, their percentage share, impact in terms of ACPP, share of international collaborative papers and $\mathrm{H}$-index value have been growing as shown in Table 3 . The cumulative contribution of PGIMER under eight broad subjects during 1999 to 2008 varies from 0.48 to $84.44 \%$. According to Scopus database there is some overlapping in the coverage under different subject areas and as a result the total output, if added will become more than 100\% (Table 3).

Considering the individual contribution of these eight broad subjects, it was observed that medicine contributed the highest number $(4,036)$ of publications with $84.4 \%$ share in institute cumulative publication output during 1999 to

\begin{tabular}{cccccc}
\multicolumn{6}{c}{ Table 1: Publications output of PGIMER (1999-2008) } \\
\hline Years & TP & TC & ACPP & ICP & ICP(\%) \\
\hline 1999 & 372 & 888 & 2.39 & 22 & 5.91 \\
2000 & 332 & 651 & 1.96 & 9 & 2.71 \\
2001 & 376 & 900 & 2.39 & 15 & 3.99 \\
2002 & 379 & 803 & 2.12 & 9 & 2.37 \\
2003 & 442 & 1234 & 2.79 & 29 & 6.56 \\
2004 & 507 & 1485 & 2.93 & 39 & 7.69 \\
2005 & 553 & 1609 & 2.91 & 47 & 8.5 \\
2006 & 623 & 1309 & 2.10 & 45 & 7.22 \\
2007 & 585 & 489 & 0.84 & 35 & 5.98 \\
2008 & 602 & 95 & 0.16 & 39 & 6.48 \\
\hline Total & 4771 & 9463 & 1.98 & 289 & 6.06 \\
\hline
\end{tabular}

TP: Total publications; TC: Total citations; ACPP: Average citation per publication; ICP: International collaborative publications

\begin{tabular}{lccccccc}
\multicolumn{7}{c}{ Table 2: Distribution of international collaborative publications of PGIMER (1999-2008) } \\
\cline { 2 - 7 } Type of publications & \multicolumn{7}{c}{ Number of publications } \\
\cline { 2 - 7 } & TP & TC & TP & TC & TP & TC \\
& $(1999-2003)$ & $(1999-2003)$ & $(2004-2008)$ & $(2004-2008)$ & $(1999-2008)$ & $(1999-2008)$ \\
\hline Total publications & 1,901 & 4,476 & 2,870 & 4,987 & 4,771 & 9,463 \\
Total international & 84 & 595 & 205 & 682 & 289 & 1,277 \\
Collaborative publications & & & & & \\
\hline
\end{tabular}

TP: Total publications; TC: Total citations 
2008, followed by biochemistry, genetics and molecular biology (562 papers and $11.76 \%$ share), immunology and microbiology (319 papers and 6.57\% share), pharmacology, toxicology and pharmaceutics (281 papers and 5.88\% share), neurology (212 papers and $4.44 \%$ share) and public health (86 papers and $1.80 \%$ share; Table 4 ). Of these eight broad subjects, the five subjects witnessed the rise in its publication share from 1999 to 2003 and 2004 to 2008: Medicine from 82.9 to $85.5 \%$, public health from 1.5 to $1.9 \%$, dentistry from 0.6 to $0.8 \%$ and nursing from 0.2 to $0.7 \%$. However, in three broad subjects, there was a decline in publication share from 1999 to 2003 and 2004 to 2008 biochemistry, genetics and molecular biology from 11.8 to $11.7 \%$, immunology and microbiology from 6.8 to $6.6 \%$ and pharmacology, toxicology and pharmaceutics from 7.87 to $4.46 \%$ (Table 4).

Among the eight broad subjects, the highest impact per paper (3.53) is scored by immunology and microbiology during 1999 to 2008, followed by biochemistry, genetics and molecular biology (2.53), pharmacology, toxicology and pharmaceutics (2.49), public health (2.17), nursing
(1.96), medicine (1.88), neurology (1.66) and dentistry (0.62). The average impact factor per paper (ACPP) recoded by four subjects has increased from 1999 to 2003 and 2004 to 2008 as follows: Immunology and microbiology (3.44-3.60), pharmacology, toxicology and pharmaceuticals (2.34-2.67), dentistry (0.55-0.65) and nursing (1.0-2.1). In contrast, ACPP has decreased in four subjects: Medicine (2.33-1.59), biochemistry, genetics and molecular biology (3.15-2.11), neurology (1.73-1.57) and public health from 3.48 to 1.53 (Table 4 ).

On considering the international collaborative publication output under these broad subjects, it was observed that immunology and microbiology contributed the largest share of $11.9 \%$ share in its total research output during 1999 to 2008, followed by biochemistry, genetics and molecular biology (8.9\%), neurology (7.1\%), medicine (6.1\%) and pharmacology, toxicology and pharmaceutics (4.3\%), public health (1.4\%), dentistry $(0.7 \%)$ and nursing $(0.3 \%)$. Among these broad subjects, all other subjects (except public health and dentistry) showed increase in international collaborative publication share from 1999 to

\begin{tabular}{|c|c|c|c|c|c|c|c|}
\hline $\begin{array}{l}\text { Subjects } \\
(1999-2003)\end{array}$ & $\begin{array}{c}T P \\
(1999-2003)\end{array}$ & $\begin{array}{c}\text { TC } \\
(2004-2008)\end{array}$ & $\begin{array}{c}T P \\
\text { (2004-2008) }\end{array}$ & $\begin{array}{c}\text { TC } \\
(1999-2008)\end{array}$ & $\begin{array}{c}T P \\
(1999-2008)\end{array}$ & $T C$ & $H$-index \\
\hline Medicine & 1,579 & 3,684 & 2,457 & 3,902 & 4,036 & 7,586 & 35 \\
\hline $\begin{array}{l}\text { Biochemistry, } \\
\text { genetics and } \\
\text { molecular biology }\end{array}$ & 225 & 708 & 337 & 712 & 562 & 1,420 & 19 \\
\hline $\begin{array}{l}\text { Immunology and } \\
\text { microbiology }\end{array}$ & 130 & 447 & 189 & 680 & 319 & 1,127 & 21 \\
\hline $\begin{array}{l}\text { Pharmacology, } \\
\text { toxicology and } \\
\text { pharmaceutics }\end{array}$ & 150 & 351 & 131 & 350 & 281 & 701 & 19 \\
\hline Public health & 29 & 101 & 56 & 86 & 85 & 187 & 11 \\
\hline Neurology & 119 & 206 & 93 & 146 & 212 & 352 & 14 \\
\hline Dentistry & 11 & 6 & 23 & 15 & 34 & 21 & 5 \\
\hline Nursing & 3 & 3 & 20 & 42 & 23 & 45 & 4 \\
\hline
\end{tabular}

TP: Total publications; TC: Total citations; ACPP: Average citation per publication; H-index: Distribution of citation

\begin{tabular}{|c|c|c|c|c|c|c|c|c|c|}
\hline \multirow[t]{2}{*}{ Subjects } & \multicolumn{3}{|c|}{$T P$} & \multicolumn{3}{|c|}{$T C$} & \multicolumn{3}{|c|}{ ACPP } \\
\hline & $1999-2003$ & $2004-2008$ & Total & $1999-2003$ & $2004-2008$ & Total & $1999-2003$ & $2004-2008$ & Total \\
\hline Medicine & 1,579 & 2,457 & 4,036 & 3,684 & 3,902 & 7,586 & 2.33 & 1.59 & 1.88 \\
\hline $\begin{array}{l}\text { Biochemistry, } \\
\text { genetics and } \\
\text { molecular biology }\end{array}$ & 225 & 337 & 562 & 708 & 712 & 1,420 & 3.15 & 2.11 & 2.53 \\
\hline $\begin{array}{l}\text { Immunology and } \\
\text { microbiology }\end{array}$ & 130 & 189 & 319 & 447 & 680 & 1127 & 3.44 & 3.60 & 3.53 \\
\hline $\begin{array}{l}\text { Pharmacology, } \\
\text { toxicology and } \\
\text { pharmaceutics }\end{array}$ & 150 & 131 & 281 & 351 & 350 & 701 & 2.34 & 2.67 & 2.49 \\
\hline Public health & 119 & 93 & 212 & 206 & 146 & 352 & 1.73 & 1.57 & 1.66 \\
\hline Neurology & 29 & 56 & 86 & 101 & 86 & 187 & 3.48 & 1.53 & 2.17 \\
\hline Dentistry & 11 & 23 & 34 & 6 & 15 & 21 & 0.55 & 0.65 & 0.62 \\
\hline Nursing & 3 & 20 & 23 & 3 & 42 & 45 & 1.00 & 2.1 & 1.96 \\
\hline
\end{tabular}

TP: Total publication; TC: Total citation; ACPP: Average citation per publication 
2003 and 2004 to 2008: Medicine from 4.31 to 7.17\%, biochemistry, genetics and molecular biology from 6.2 to $10.7 \%$, immunology and microbiology from 11.5 to $12.2 \%$, pharmacology, toxicology and pharmaceutics from 1.3 to $7.6 \%$, neurology from 3.4 to $11.8 \%$ and nursing from 0.0 to $0.5 \%$ from 1999 to 2003 and 2004 to 2008 (Table 5).

\section{Contribution to Various Diseases}

In this section, the research output of PGIMER to various diseases has been analyzed during 1999-2008. The maximum research output has been in cancer with 430 papers, followed by cardiovascular disease (373 papers), tuberculosis (267 papers), diabetes (140 papers), pneumonia (119 papers), AIDS (94 papers), hepatitis (93 papers), diarrheal diseases (82 papers), asthma (79 papers), respiratory infection (69 papers), leprosy (47 papers), malaria (31 papers), typhoid (19 papers), kala azar (15 papers), polio (14 papers), dengue (10 papers), cholera (10 papers), Japanese encephalitis (10 papers), rabies (9 papers), vibrio cholera (7 papers), leptospirosis (6 papers), meningococcal meningitis (5 papers), west nile virus (3 papers), chikungunya (2 papers), etc.

\section{Research Output under Different Departments}

There are total 47 departments in PGIMER, of which 30 are classified as clinical departments, 12 as paraclinical and five as nonclinical departments. The research output and impact of PGIMER under these different departments during 1999 to 2008 is given in Table 6.

Among the clinical departments, the maximum research output comes from pulmonary medicine department with 564 papers, followed by gastroenterology (286 papers), internal medicine (282 papers), radiodiagnosis (265 papers), dermatology (248 papers), anesthesia (209 papers), etc. In terms of impact, nephrology department scored the highest impact with 3.07 citations received per paper, followed by dermatology (2.40), hematology (2.34), pediatrics (2.12), etc. (Table 6).

Similarly, under paraclinical departments, the maximum research output comes from histopathology department with 353 papers, followed by pharmacology (198 papers), medical microbiology (171 papers), experimental medicine (148 papers), etc. Among these departments, medical microbiology scored highest average citations per paper (ACPP) with 3.07 citations, followed by experimental medicine (2.36), pharmacology (2.21), parasitology (2.17), etc. (Table 6).

Among nonclinical departments, biochemistry department published the highest number of papers (168), followed by biophysics (41), biostatics (11) and anatomy (3 papers). In terms of impact, the highest impact per paper of 3.74 was scored by biochemistry, followed by biostatics (3.64), biophysics (2.68) and anatomy (2.33; Table 6).

\section{International Collaborative Research Output of PGIMER with Major Collaborative Countries}

Based on the publication data, it was observed that PGIMER has written collaborative papers with 20 partner countries during 1999 to 2008 (Table 7). The international collaborative papers of the institute contributed $6.1 \%$ share (with 289 papers) in the cumulative publications output of PGIMER during 1999 to 2008. The institute witnessed the increase in the share of international collaborative papers from $4.42 \%$ (84 papers) in 1999 to 2003 to $7.14 \%$ (205 papers) during 2004 to 2008.

Among the various collaborating countries, United States contributed the largest share of $38.4 \%$ share with 118 papers in cumulative output of PGIMER during 1999 to 2008, followed by United Kingdom (20.5\% share, 63 papers), Canada (10.10\% share, 31 papers), Australia (4.89\% share,

\begin{tabular}{|c|c|c|c|c|c|c|c|}
\hline \multirow[t]{2}{*}{ Subjects } & \multicolumn{3}{|c|}{ ICP } & \multicolumn{3}{|c|}{ Share of ICP (\%) } & \multirow[t]{2}{*}{ H-index } \\
\hline & $1999-2003$ & $2004-2008$ & $1999-2008$ & $1999-2003$ & $2004-2008$ & $1999-2008$ & \\
\hline Medicine & 68 & 176 & 244 & 4.31 & 7.16 & 6.05 & 35 \\
\hline $\begin{array}{l}\text { Biochemistry, genetics } \\
\text { and molecular biology }\end{array}$ & 14 & 36 & 50 & 6.22 & 10.68 & 8.90 & 19 \\
\hline $\begin{array}{l}\text { Immunology and } \\
\text { microbiology }\end{array}$ & 15 & 23 & 38 & 11.54 & 12.17 & 11.91 & 21 \\
\hline $\begin{array}{l}\text { Pharmacology, } \\
\text { toxicology and } \\
\text { pharmaceutics }\end{array}$ & 2 & 10 & 12 & 1.33 & 7.63 & 4.27 & 18 \\
\hline Neurology & 4 & 11 & 15 & 3.36 & 11.83 & 7.08 & 14 \\
\hline Public health & 29 & 56 & 86 & 2.38 & 0.65 & 1.39 & 11 \\
\hline Dentistry & 11 & 23 & 34 & 1.19 & 0.48 & 0.69 & 4 \\
\hline Nursing & 3 & 20 & 23 & 0.00 & 0.48 & 0.34 & 5 \\
\hline Total & 84 & 206 & 290 & 4.31 & 7.07 & 5.96 & 38 \\
\hline
\end{tabular}

ICP: International collaborative papers 
15 papers), Germany (4.23\% share, 13 papers), Italy (3.26\% share, 10 papers), France (3.26\% share, 10 papers), etc.

\section{Patterns of Research Communication}

The list of top 40 productive Indian and foreign journals in which the staff to PGIMER have published their research output during 1999 to 2008 is presented in Table 8. These 40 highly productive Indian and foreign journals together contributed $40 \%$ share in the cumulative publication output of PGIMER during 1999 to 2008. The cumulative output of these 40 productive journals in total publications output of PGIMER showed decline from 45.8\% in 1999 to 2003 to $36.3 \%$ in 2004 to 2008 . Of these 40 journals, 18 journals are domestic and 22 foreign. The Indian journals contributed higher percentage share (23.9\%) than the foreign journals (16.1\%) in total productivity of PGIMER during 1999 to 2008. The dominant subject areas of productive journals were medicine, pediatrics, dermatology and pathology.

\section{High Cited Papers}

Out of 100 high cited papers, 90 appeared as articles, 5 as reviews, 4 as conference paper and 1 as letter. Out of 100 highcited papers, 12 papers involve international collaboration (8 multilateral and 4 bilateral), 6 national collaboration and 21 interdepartmental collaboration. Sixtyone papers involve zero collaboration. The high cited papers appeared in 79 Indian and foreign journals. The maximum number (6) papers were published in international journal

\begin{tabular}{|c|c|c|c|}
\hline Departments & $T P$ & $T C$ & $A C P P$ \\
\hline \multicolumn{4}{|l|}{ Clinical departments } \\
\hline Department of pulmonary medicine & 564 & 594 & 1.05 \\
\hline Department of gastroenterology & 286 & 460 & 1.61 \\
\hline Department of internal medicine & 282 & 578 & 2.05 \\
\hline Department of radiodiagnosis & 265 & 489 & 1.85 \\
\hline Department of dermatology & 248 & 595 & 2.4 \\
\hline Department of anesthesia & 209 & 257 & 1.23 \\
\hline Department of psychiatry & 168 & 289 & 1.72 \\
\hline Department of endocrinology & 134 & 249 & 1.86 \\
\hline Department of cardiology & 127 & 182 & 1.43 \\
\hline Department of nephrology & 121 & 371 & 3.07 \\
\hline Department of neurosurgery & 115 & 151 & 1.31 \\
\hline Department of hepatology & 114 & 267 & 2.34 \\
\hline Department of otolaryngology & 114 & 133 & 1.17 \\
\hline Department of pediatrics & 97 & 206 & 2.12 \\
\hline Department of urology & 87 & 177 & 2.03 \\
\hline Department of radiotherapy & 77 & 105 & 1.36 \\
\hline Department of general surgery & 76 & 158 & 2.08 \\
\hline Department of nuclear medicine & 70 & 144 & 2.06 \\
\hline Department of community medicine & 68 & 110 & 1.62 \\
\hline Department of plastic surgery & 68 & 41 & 0.6 \\
\hline Department of orthopedics & 49 & 36 & 0.73 \\
\hline Department of oral health sciences & 32 & 19 & 0.59 \\
\hline Department of pediatric surgery & 29 & 31 & 1.07 \\
\hline Department of cardiovascular and thoracic surgery & 22 & 16 & 0.73 \\
\hline Department of cytology and gynehistopathology & 11 & 21 & 1.91 \\
\hline Department of obstetric and gynecology & 1 & 0 & 0 \\
\hline \multicolumn{4}{|l|}{ Paraclinical departments } \\
\hline Department of histopathology & 353 & 567 & 1.61 \\
\hline Department of pharmacology & 198 & 437 & 2.21 \\
\hline Department of medical microbiology & 171 & 520 & 3.04 \\
\hline Department of experimental medicine & 148 & 349 & 2.36 \\
\hline Department of immunopathology & 86 & 179 & 2.08 \\
\hline Department of parasitology & 76 & 165 & 2.17 \\
\hline Department of hematology & 49 & 101 & 2.06 \\
\hline Department of virology & 38 & 60 & 1.58 \\
\hline Department of college of nursing & 24 & 28 & 1.17 \\
\hline Department of forensic Medicine & 18 & 30 & 1.67 \\
\hline Department of biostatistics & 11 & 40 & 3.64 \\
\hline \multicolumn{4}{|l|}{ Nonclinical departments } \\
\hline Department of biochemistry & 168 & 628 & 3.74 \\
\hline Department of biophysics & 41 & 110 & 2.68 \\
\hline Department of biostatistics & 11 & 40 & 3.64 \\
\hline Department of anatomy & 3 & 7 & 2.33 \\
\hline
\end{tabular}

TP: Total publication; TC: Total citation; ACPP: Average citation per publication 
of dermatology, followed by 3 papers each in acta radiologica, digestive diseases and sciences, journal of gastroenterology and heptology, Lancet and 2 papers each in acta pediatrica, dermatology, FEMS microbiology, gastrointestinal endoscopy, international journal of antimicrobial agents, journal of child neurology, pediatric critical care medicine and tuberculosis, etc. Out of 100 high cited papers, one paper received citations above 100, 1 paper in citation range of 81 to 90,2 papers in citation range of 61 to 70,2 papers in citation range of 51 to 60,4 papers in citation range of 41 to 50, 14 papers in citation range of 31 to 40,23 papers in citation range of 21 to 30 and 53 papers in citation range of 11 to 20 .

The high cited papers involve contribution from 27 departments and 229 authors. The maximum representation were from department of dermatology with 13 papers involving 17 authors, followed by pediatrics department (10 papers involving 21 authors), biochemistry department (10 papers involving 12 authors), hepatology department (9 papers involving 16 authors), radiodiagnosis department (8 papers involving 13 authors), internal medicine department (7 papers involving 13 authors), gastroentrology department (6 papers involving 17 authors), pulmonary medicine department (6 papers involving 13 authors), experimental medicine and biotechnology department (6 papers involving 10 authors), ophthalmology department (5 papers involving 8 authors), nephrology department (5 papers involving 6 authors), histopathology department (5 papers involving 8 authors), general surgery department
(4 papers involving 7 authors), pharmacology department (4 papers involving 9 authors), surgery department ( 3 papers involving 3 authors), cardiology department (3 papers involving 8 authors), medical microbiology department (3 papers involving 18 authors), psychiatry department (3 papers involving 7 authors), microbiology department (3 papers involving 2 authors), public health department (3 papers involving 1 author), nuclear medicine department (3 papers involving 3 authors), cytology department (3 papers involving 4 authors), obstetrics and gynecology department (2 papers involving 2 authors), parasitology department (2 papers involving 6 authors), pathology department (2 papers involving 1 author), anesthesiology department (2 papers involving 2 authors) and biophysics department (2 papers involving 2 authors).

A list of high cited paper in the Table 9.

\section{SUMMARY AND DISCUSSION}

The PGIMER faculty published 4,771 papers during 1999 to 2008 , with an average annual growth rate of $5.9 \%$. Its publication output increased from 1,901 papers to 2,870 papers from 1999 to 2003 and 2004 to 2008, showing growth rate $51 \%$. Its faculty publications registered an average impact of 1.98 citations per paper during 1999 to 2008, which decreased from 2.35 to 1.74 citations per paper from 1999 to 2003 and 2004 to 2008.

The individual contribution from PGIMER to eight subjects during 1999 to 2008 varied from 0.5 to $84.4 \%$, with highest contribution in medicine, followed by

\begin{tabular}{|c|c|c|c|c|}
\hline \multirow[t]{2}{*}{ S. no. } & \multirow[t]{2}{*}{ Collaborating country } & \multicolumn{3}{|c|}{ Number of international collaborative publications } \\
\hline & & $1999-2008$ & $2004-2008$ & Total \\
\hline 1 & United States & 43 & 75 & 118 \\
\hline 2 & United Kingdom & 15 & 48 & 63 \\
\hline 3 & Canada & 7 & 24 & 31 \\
\hline 4 & Australia & 4 & 11 & 15 \\
\hline 5 & Germany & 5 & 8 & 13 \\
\hline 6 & Italy & 4 & 6 & 10 \\
\hline 7 & France & 2 & 8 & 10 \\
\hline 8 & Spain & 1 & 7 & 8 \\
\hline 9 & Israel & 1 & 6 & 7 \\
\hline 10 & Sweden & 3 & 3 & 6 \\
\hline 11 & Japan & 3 & 2 & 5 \\
\hline 12 & Singapore & 1 & 4 & 5 \\
\hline 13 & Switzerland & 1 & 3 & 4 \\
\hline 14 & Columbia & 1 & 2 & 3 \\
\hline 15 & China & 1 & 1 & 2 \\
\hline 16 & Taiwan & 1 & 1 & 2 \\
\hline 17 & Mexico & 0 & 2 & 2 \\
\hline 18 & Russia & 0 & 1 & 1 \\
\hline 19 & Poland & 0 & 1 & 1 \\
\hline \multirow[t]{4}{*}{20} & Hungary & 0 & 1 & 1 \\
\hline & Total ICP papers & 93 & 214 & 307 \\
\hline & PGIMER output & 1,901 & 2,870 & 4,771 \\
\hline & Share of ICP(\%) & $4.89 \%$ & $7.46 \%$ & $6.06 \%$ \\
\hline
\end{tabular}


biochemistry, genetics and molecular biology, immunology and microbiology, pharmacology, toxicology and pharmaceutics, neurosciences, public health, dentistry and nursing. Among these eight subjects, the publication share of medicine, public health, dentistry and nursing has increased, while those of biochemistry, genetics and molecular biology, immunology and microbiology and pharmacology, toxicology and pharmaceutics have decreased from 1999 to 2003 and 2004 to 08 . The largest citation impact (3.53) has been registered by immunology and microbiology during 1999 to 2008, followed by biochemistry, genetics and molecular biology, pharmacology, toxicology and pharmaceutics and public health (2.17-2.53), nursing, medicine and neurosciences (1.66-1.96) and dentistry (0.62). The average impact factor per paper recorded by immunology and microbiology, pharmacology, toxicology and pharmaceutical, dentistry and nursing has increased, while those of medicine, biochemistry, genetics and molecular biology, neurology and public health has decreased from 1999 to 2003 and 2004 to 2008 .

Among the contribution of PGIMER to various diseases during 1999 to 2008, the maximum research output has been in cancer with 430 papers, followed by cardiovascular disease (373 papers), tuberculosis (267 papers), diabetes (140 papers), pneumonia (119 papers), AIDS (94 papers), hepatitis (93 papers), diarrheal diseases (82 papers), asthma (79 papers), respiratory infection (69 papers), leprosy (47 papers), malaria (31 papers), etc.

Among the 47 departments of PGIMER, the maximum research output comes from pulmonary medicine department with 564 papers, followed by departments of histopathology gastroenterology, internal medicine, radiodiagnosis, dermatology, anesthesia (209-353 papers), pharmacology,

\begin{tabular}{|c|c|c|c|c|}
\hline \multirow[t]{2}{*}{ S. no. } & \multirow[t]{2}{*}{ Journals } & \multicolumn{3}{|c|}{ Number of papers } \\
\hline & & $1999-2003$ & $2004-2008$ & $1999-2008$ \\
\hline 1 & Indian Pediatrics & 100 & 90 & 190 \\
\hline 2 & Indian Journal of Pediatrics & 68 & 74 & 142 \\
\hline 3 & Indian Journal of Pathology and Microbiology & 38 & 62 & 100 \\
\hline 4 & Neurology India & 77 & 19 & 96 \\
\hline 5 & Indian Journal of Medical Research & 34 & 60 & 94 \\
\hline 6 & Indian Journal of Gastroenterology & 37 & 41 & 78 \\
\hline 7 & Tropical Gastroenterology & 44 & 31 & 75 \\
\hline 8 & Journal of Association of Physicians of India & 45 & 29 & 74 \\
\hline 9 & Molecular and Cellular Biochemistry & 19 & 45 & 64 \\
\hline 10 & Journal of Gastroenterology and Hepatology & 24 & 32 & 56 \\
\hline 11 & Journal of Anesthesiology Clinical Pharmacology & 29 & 27 & 56 \\
\hline 12 & Indian Journal of Chest Diseases and Allied Sciences & 22 & 26 & 48 \\
\hline 13 & Indian Journal of Ophthalmology & 17 & 26 & 43 \\
\hline 14 & Anesthesia and Analgesia & 12 & 31 & 43 \\
\hline 15 & Diagnostic Cytopathology & 26 & 16 & 42 \\
\hline 16 & Paediatric Anesthesia & 2 & 39 & 41 \\
\hline 17 & Journal of Dermatology & 8 & 30 & 38 \\
\hline 18 & Bulletin of Medical Education and Research & 2 & 34 & 36 \\
\hline 19 & Methods and Findings in Experimental and Clinical Pharmacology & 25 & 8 & 33 \\
\hline 20 & Indian Journal of Dermatology Venereology and Leprology & 7 & 26 & 33 \\
\hline 21 & International Journal of Gynecology and Obstetrics & 14 & 19 & 33 \\
\hline 22 & Analytical and Quantitative Cytology and Histology & 9 & 22 & 31 \\
\hline 23 & Journal of the European Academy of Dermatology and Venereology & 17 & 14 & 31 \\
\hline 24 & Journal of Postgraduate Medicine & 9 & 20 & 29 \\
\hline 25 & Journal of Pediatric Surgery & 17 & 12 & 29 \\
\hline 26 & International Journal of Dermatology & 14 & 15 & 29 \\
\hline 27 & Acta Cytologica & 17 & 12 & 29 \\
\hline 28 & Indian Heart Journal & 15 & 13 & 28 \\
\hline 29 & Gastrointestinal Endoscopy & 13 & 15 & 28 \\
\hline 30 & Postgraduate Medical Journal & 18 & 10 & 28 \\
\hline 31 & Journal of Tropical Pediatrics & 15 & 11 & 26 \\
\hline 32 & Digestive Diseases and Sciences & 7 & 18 & 25 \\
\hline 33 & Indian Journal of Experimental Biology & 14 & 10 & 24 \\
\hline 34 & Indian Journal of Medical Sciences & 7 & 17 & 24 \\
\hline 35 & Indian Journal of Otolaryngology and Head and Neck Surgery & 9 & 15 & 24 \\
\hline 36 & JK Science & 8 & 15 & 23 \\
\hline 37 & Lancet & 6 & 17 & 23 \\
\hline 38 & Cytopathology & 8 & 15 & 23 \\
\hline 39 & Transplantation Proceedings & 11 & 11 & 22 \\
\hline 40 & American Journal of Hematology & 7 & 14 & 21 \\
\hline
\end{tabular}


medical microbiology, psychiatry, biochemistry experimental medicine, endocrinology (134-198 papers), etc. In terms of citation impact, highest impact per paper of 3.74 was scored by biochemistry, followed by biostatics, nephrology, medical microbiology (3.07-3.64) and biophysics, dermatology, experimental medicine), hepatology, anatomy, pharmacology, parasitology, pediatrics (2.122.68), etc.

The international collaborative papers of the institute contributed 6.1\% share (with 289 papers) in the cumulative publication output of PGIMER during 1999 and 2008, which increased from 4.4 to $7.1 \%$ from 1999 to 2003 and 2004 to 2008. United States contributed the largest share of $38.4 \%$ international collaborative papers in the institute total publications output, followed by United Kingdom (20.52\% share), Canada (10.1\% share), Australia (4.9\% share), Germany (4.2\% share), Italy (3.3\% share), France (3.3\% share), etc.

Out of 100 high cited papers, 12 papers involve international collaboration (8 multilateral and 4 bilateral) and national collaboration. The high cited papers appeared in 79 Indian and foreign journals, with maximum number (6) papers were published in international journal of dermatology, followed by 3 papers each in acta radiologica, digestive diseases and sciences, journal of gastroenterology and heptology, Lancet, etc. Out of 100 high cited papers, one paper received citations above 100, 1 paper in citation range of 81 to 90, 2 papers in citation range of 61 to 70 , 2 papers in citation range of 51 to 60,4 papers in citation range of 41 to 50, 14 papers in citation range of 31 to 40 , 23 papers in citation range of 21 to 30 and 53 papers in citation range of 11 to 20 .

The high cited papers involve contribution from 27 departments and 229 authors. The maximum representation were from department of dermatology with 13 papers involving 17 authors, followed by pediatrics department (10 papers involving 21 authors), biochemistry department (10 papers involving 12 authors), heptology department (9 papers involving 16 authors), radiodiagnosis department (8 papers involving 13 authors), internal medicine department (7 papers involving 13 authors), gastroentrology department (6 papers involving 17 authors), pulmonary medicine department (6 papers involving 13 authors), experimental medicine and biotechnology department (6 papers involving 10 authors), etc.

\section{REFERENCES}

1. Jeevan VKJ, Gupta BM. A scientometric profile of research output from Indian Institute of Technology, Kharagpur. Scientometrics 2002;53(1):165-68.

2. Jeevan VKJ, Gupta BM. R and D performance of different departments of IIT Kharagpur: A scientometric study based on publications. J Libr Inf Sci 2001; 26(2):129-43.

3. Singh Y, Gupta BM, Kumar S. Research contributions and impact of research of Indian Institute of Technology Roorkee: 1993-2001. Ann Libr Inf Stud 2005;52(1):8-14.

\begin{tabular}{|c|c|c|}
\hline Departments & Total papers & Total authors \\
\hline Dermatology & 13 & 17 \\
\hline Pediatrics & 10 & 21 \\
\hline Biochemistry & 10 & 12 \\
\hline Hepatology & 9 & 16 \\
\hline Radiodiagnosis & 8 & 13 \\
\hline Internal medicine & 7 & 9 \\
\hline Gastroenterology & 6 & 17 \\
\hline Pulmonary medicine & 6 & 13 \\
\hline Experimental Medicine and biotechnology & 6 & 10 \\
\hline Ophthalmology & 5 & 8 \\
\hline Nephrology & 5 & 6 \\
\hline Histopathology & 5 & 8 \\
\hline General surgery & 4 & 7 \\
\hline Pharmacology & 4 & 9 \\
\hline Surgery & 3 & 3 \\
\hline Cardiology & 3 & 8 \\
\hline Medical microbiology & 3 & 18 \\
\hline Psychiatry & 3 & 7 \\
\hline Microbiology & 3 & 2 \\
\hline Public health & 3 & 1 \\
\hline Nuclear medicine & 3 & 3 \\
\hline Cytology & 3 & 4 \\
\hline Obstetrics and gynecology & 2 & 2 \\
\hline Parasitology & 2 & 6 \\
\hline Pathology & 2 & 1 \\
\hline Anesthesiologist & 2 & 2 \\
\hline Biophysics & 2 & 6 \\
\hline
\end{tabular}


4. Millionth K, Gupta BM, Dhawan SM. Growth and impact of research output of University of Mysore 1996-2006: A case study. Ann Libr Inf Stud 2008;55(5): 185-95.

5. Adarsh B, Gupta BM. Growth and impact of research output of Government Medical College and Hospital, Chandigarh: A case study. Ann Libr Inf Stud 2009;56(2):86-94.

\section{ABOUT THE AUTHORS}

\section{Raj Kumar (Corresponding Author)}

Senior Library and Information Officer, Tulsi Das Library Postgraduate Institute of Medical Education and Research, Chandigarh India, e-mail: rajkumar196@yahoo.co.in

\section{BM Gupta}

Emeritus Scientist, National Institute of Science Technology and Development Studies, Pusa, New Delhi, India

\section{JS Thakur}

Additional Professor, School of Public Health, Postgraduate Institute of Medical Education and Research, Chandigarh, India

\section{RK Sharma}

Additional Professor, Department of Hospital Administration Postgraduate Institute of Medical Education and Research Chandigarh, India

\section{Kiran Baidwan}

Senior Librarian and Information Assistant, Tulsi Das Library Postgraduate Institute of Medical Education and Research Chandigarh, India

\section{Adrash Bala Goyal}

Assistant Librarian, Government Medical College \& Hospital Chandigarh, India 